\title{
Oncology at FMUSP
}

\section{Maria Mitzi Brentani}

$\mathrm{T}$ he founding of the "Centro de Oncologia CEON", Oncology Center, in 1963, began the history of Oncology at the University of São Paulo's Faculty of Medicine (FMUSP). Professor Charles Edward Corbett, as its executive director, at the meeting of the Congregation on December 15, 1969 requested that the facilities of the Oncology Center be located in an area between the Central Vivarium and the "Instituto Oscar Freire". The request was approved with the exception of Professor Carlos Junqueira, holder of the Histology chair, who proposed the creation of an Oncology Research Center in the Faculty of Medicine. This Research Center would have as its objectives teaching activities and basic and clinical research in Oncology, giving the CEON a unique profile between teaching and research activities, therefore avoiding possible implications of double services. Professor Charles Corbett, on May 12, 1971, in agreement with the Rectory, asked the Congregation to transfer doctors Ricardo R. Brentani, Maria Mitzi Brentani and Arnaldo Soares Annes da Silva who had been relocated to the Institute of Chemistry during the University Reform in 1970. At that time all the basic chairs in FMUSP, including Biochemistry had been transferred to the campus "Cidade Universitária". The researchers mentioned returned to FMUSP and
Dr. R. Brentani became part of the CEON's Technical and Scientific Committee, with professors Charles Edward Corbett, Álvaro Magalhães and Carlos Campos Junqueira. A research laboratory named Experimental Oncology Laboratory was set up on the $4^{\text {th }}$ floor of the FMUSP occupying part of the area where the Department of Biochemistry's Laboratory, previously operated.

Dr. Brentani's post-graduate students, Shigueko Sonohara and Cecilia dos Santos and Luisa Lina Villa, as a post-doctoral fellow, accompanied his return to the FMUSP.

One of the projects developed in the Experimental Oncology Laboratory at that time by Professor R. Brentani (who in 1980 became Full Professor of Clinical Therapy II - Oncology), Dr. Luisa Villa and Dr. Francisco Bolivar, from the National University of Mexico, was the achievement of insulin cloning through a construction of a bacterium containing the gene for human insulin. With this work the authors as winners of the $10^{\mathrm{TH}}$ National Brazilian Invention Contest were awarded the "Premio Governador do Estado", in 1982. This project marks the early use of Molecular Biology in the Experimental Oncology Laboratory, which expanded to completion of the Cancer Genome Project investigating the growing complexity of the neoplastic process.

Retired Assistant Professor of the University of São Paulo's Faculty of Medicine (FMUSP), Department of Radiology and Oncology, LIM-24 HCFMUSP's Laboratory of Medical Research.

Mailing address: University of São Paulo, University of São Paulo's Faculty of Medicine, Department of Radiology. Avenida Dr. Arnaldo, 455, $4^{\circ}$ andar, sala 4112. Cerqueira César. CEP: 01246-903 - São Paulo, SP, Brasil. Email: mbrentani@lim24.fm.usp.br 
Simultaneously, aiming to develop a line of research on tumor markers, I devised the methodology to define hormone receptors in breast cancer. This definition is of great clinical importance, since it defines the type of treatment to be followed by patients after surgery. The collaboration with Professor João Sampaio Goes, teacher at the Department of Pathology, FMUSP, who, in 1973 was nominated Director of the National Cancer Division, attached to the Ministry of Health, was of extreme importance. Together with the implementation of a program for the detection and prevention of breast cancer, Professor Goes proposed to develop some basic points, including a field of cancer research and recording, as well as patient care. In order to enable this project the "Fundação Centro de Pesquisa em Oncologia - FOSP" was created in 1974. Initially it operated in the Nuclear Medicine Center at the FM/HC and was later transferred to its own building. The patients treated at FOSP underwent surgery at the IBCC Hospital and for several years we extracted hormone receptors in samples from these patients or in samples coming from various other hospitals in the city of São Paulo. This basic and clinical lines of research resulted in the publishing of several studies and in the development of master and doctoral theses.

In 1975 an agreement was reached between the "Hospital das Clínicas - HC") and FMUSP to establish the "Laboratórios de Investigação Médica - LIM" and some of these laboratories which already existed in the HC migrated to the FMUSP building. The Experimental Oncology Lab (under the responsibility of Prof. R.
Brentani and Dr. M. M. Brentani) located on the 4th floor, East wing, room 5 (Clinical Therapy) was included as one of the LIMs with No. 24 in 1977 by the Decree 9720/77 (regulation 9720/77).

In 1982, Professor Brentani was appointed director of the Ludwig Institute for Cancer Research São Paulo branch, which operated in the AC Camargo Hospital building, where a Molecular Biology laboratory was established with the help of Dr. Luisa Lina Villa and many other investigators and students. Afterwards, Prof. Brentani was appointed president of the AC Camargo Hospital, however he did not leave his activities at the HCFMUSP Department of Radiology and Oncology nor did he stop promoting the experience and technology exchange between LIM-24 and the AC Camargo Hospital, a partnership which greatly contributed to the increase of our scientific production.

The Oncology Laboratory is gaining acknowledgment in Brazil for its research activities which continue to be performed together with other laboratories and cancer hospitals. I hope we move towards a more technological future without losing, nevertheless, the ethical and ideological goals of Prof. Brentani and of all those who began and worked for the improvement of research, teaching and professional training in Oncology within FMUSP.

I wish to thank all the members of the staff, who contributed to the maintenance of the experimental oncology laboratory through all these years, in which we faced challenges, but we also achieved many victories. 